\title{
Simulasi Pencahayaan Terowongan Tomang Siang Hari Menggunakan Lampu LED
}

\author{
Endah Setyaningsih ${ }^{1}$, Jeanny Pragantha ${ }^{2}$, dan Rizki A. Mangkuto ${ }^{3}$
}

\begin{abstract}
Tunnel lighting during the day is very dependent on sunlight, especially access zones and threshold zones. The intensity of light in the zone must be able to compensate for the intensity of sunlight in front of the tunnel. For that artificial lighting will be placed in the access zone and the threshold zone must be arranged according to the presence of sunlight in front of the tunnel. At night, the threshold zone up to the exit zone must have the same illumination and luminance, and the value is not much different from the illumination and luminance that is on public roads before and after the tunnel. But in the daytime each zone must have different illuminations and luminance. This study took data from the Tomang tunnel, this tunnel consists of tunnels in the direction of Tangerang with an estimated average vehicle speed of $60 \mathrm{~km} /$ hour. The tunnel length is $120 \mathrm{~m}$, width $7 \mathrm{~m}$, height $4 \mathrm{~m}$. The research in the form of this simulation uses LED lights, according to which currently there are 15 pieces installed, previously using 250 Watt HPS lights, as many as 20 pieces, with a distance between $6 \mathrm{~m}$ lights. The results showed that the lighting of the Tomang tunnel is currently not appropriate for daylight, because the lighting threshold zone is less able to meet the sun's luminance. As a result, during the day the threshold zone appears dark (there is a black hole phenomenon). While at night it produces excess illuminance and luminance, namely 104 lux illumination and $9.96 \mathrm{~cd} / \mathrm{m} 2$ luminance greater than SNI standard 20 lux - 25 lux and $2 \mathrm{~cd} / \mathrm{m} 2$. The use of LED lights produces higher luminance with less power, than HPS lamps.
\end{abstract}

Keyword: Tomang tunnel, threshold zone, illumination, luminance, and SNI.

\begin{abstract}
ABSTRAK: Pencahayaan terowongan pada siang hari sangat tergantung pada cahaya matahari, khususnya zona akses dan zona ambang. Intensitas cahaya pada zona tersebut harus dapat mengimbangi intensitas cahaya matahari di muka terowongan. Untuk itu pencahayaan buatan yang akan ditempatkan di zona akses dan zona ambang harus di tata sesuai adanya cahaya matahari di muka terowongan. Pada malam hari, zona ambang sampai dengan zona exit harus mempunyai iluminansi dan luminansi yang sama, dan nilainya tidak jauh berbeda dengan iluminansi dan luminansi yang ada pada jalan umum sebelum dan sesudah terowongan. Namun pada siang hari setiap zona harus mempunyai iluminansi dan luminansi yang berbeda. Penelitian ini mengambil data dari terowongan Tomang, terowongan ini terdiri dari terowongan ke arah Tangerang dengan perkiraan kecepatan rata-rata kendaraan sebesar $60 \mathrm{~km} / \mathrm{jam}$. Panjang terowongan $120 \mathrm{~m}$, lebar $7 \mathrm{~m}$, tinggi $4 \mathrm{~m}$. Penelitian yang berupa simulasi ini menggunakan lampu LED, sesuai yang saat ini terpasang sejumlah 15 buah, sebelumnya menggunakan lampu HPS 250 Watt, sebanyak 20 buah, dengan jarak antar lampu 6 m. Hasil penelitian menunjukkan bahwa pencahayaan terowongan Tomang saat ini kurang tepat untuk siang hari, karena pada zona ambang pencahayaannya kurang dapat memenuhi luminansi cahaya matahari. Akibatnya pada siang hari zona ambang nampak gelap (terjadi adanya black hole phenomena). Sementara pada malam hari menghasilkan iluminansi dan luminansi yang berlebih, yaitu iluminansi 104 lux dan luminansi 9,96 cd/m2 yang lebih besar dari standar SNI 20 lux - 25 lux dan $2 \mathrm{~cd} / \mathrm{m} 2$. Penggunaan lampu LED menghasilkan luminansi lebih tinggi dengan daya lebih minimal, dari pada lampu HPS.
\end{abstract}

Kata kunci: terowongan Tomang, zona ambang, iluminansi, luminansi, dan SNI.

\section{PENDAHULUAN}

$\mathrm{P}$ encahayaan terowongan pada siang hari sangat tergantung pada cahaya matahari, khususnya zona akses dan zona ambang. Intensitas cahaya pada zona tersebut harus dapat mengimbangi intensitas cahaya matahari di muka terowongan. Untuk itu pencahayaan buatan yang akan ditempatkan di zona akses dan zona ambang harus di tata sesuai adanya cahaya matahari di muka terowongan. Pada malam hari, zona ambang sampai dengan zona exit harus mempunyai iluminansi dan luminansi yang sama, dan nilainya tidak jauh berbeda dengan iluminansi dan luminansi yang ada pada jalan umum sebelum dan sesudah terowongan. Namun pada siang hari setiap zona harus mempunyai iluminansi dan luminansi yang berbeda.

Penelitian ini mengambil data dari terowongan Tomang, terowongan ini terdiri dari terowongan ke arah Tangerang dengan perkiraan kecepatan rata-rata kendaraan yang melintas sebesar $60 \mathrm{~km} / \mathrm{jam}$. Panjang terowongan 120 meter, lebar 7 meter, tinggi 4 meter. Penelitian yang dilakukan berupa simulasi untuk optimisasi pencahayaan muka terowongan, terutama pada zona ambang. Pada penelitian sebelumnya simulasinya menggunakan lampu HPS $250 \mathrm{~W}$, sebanyak 20 buah, jarak antar lampu 6 meter. Hasilnya telah dipublikasikan pada The 17th FSTPT International Symposium, Jember University, 22-24 August 2014. 2014, dengan judul "Tunnel Lighting For Vehicles In DKI Jakarta", dan penulisnya adalah Endah Setyaningsih, Jeanny Pragantha, dan Lydwina Wardhani.

Data dari penelitian sebelumnya digunakan dalam penelitian ini, namun jenis lampu yang digunakan adalah lampu LED. Hal ini berdasarkan adanya pemasangan 15 lampu LED dalam rangka menyambut Asian Games pada terowongan Tomang (Sumber: Kepala Suku Dinas Perindustrian dan Energi (PE) Jakarta Barat, Ery Ghazali, 4 Juli 2018, Poskota News). Adanya pemasangan 15 lampu LED ini, tentunya akan memberikan intensitas cahaya untuk terowongan Tomang yang berbeda, yang sebelumnya menggunakan lampu HPS, sebanyak 20 buah.

Menurut Standar Nasional Indonesia (SNI), Iluminansi terowongan adalah 20 lux-25 lux, dan luminansinya $2 \mathrm{~cd} / \mathrm{m}^{2}$ [BSN, 2008], dan berlaku untuk semua zona dalam terowongan, serta berlaku untuk malam

\footnotetext{
${ }^{1}$ Program Studi Teknik Elekro, Fakultas Teknik, Universitas Tarumanagara

${ }^{2}$ Program Studi Teknik Informatika, Fakultas Teknologi Informasi Universitas Tarumanagara

${ }^{3}$ Program Studi Teknik Fisika, Fakultas Teknologi Industri, Institut Teknologi Bandung
} 
dan siang hari. Namun nilai iluminansi dan luminansi dari SNI ini, lebih tepat hanya untuk standar malam hari, mengingat iluminansi malam hari untuk jalan arteri dengan akses kontrol dan jalan bebas hambatan (non terowongan) adalah 15 lux sampai dengan 20 lux dan luminansinya adalah $1,5 \mathrm{~cd} / \mathrm{m}^{2}$. Sementara itu iluminansi dan luminansi terowongan untuk pencahayaan siang hari seharusnya tidak sama untuk semua zona. SNI belum menyediakan standar pencahayaan untuk terowongan pada siang hari, untuk itu dalam penelitian ini menggunakan standar internasional, yaitu standar ANSI/IES Rp-22-11.

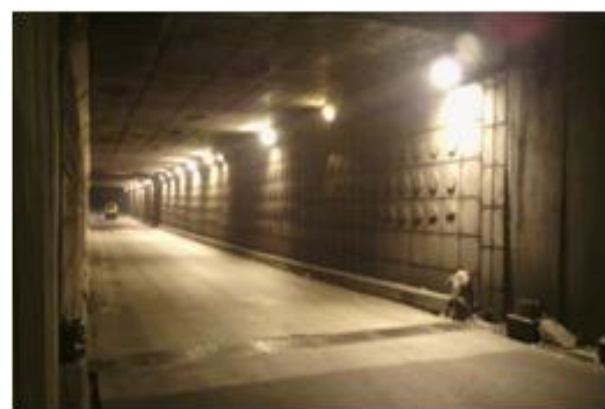

(a) Semua zona terowongan

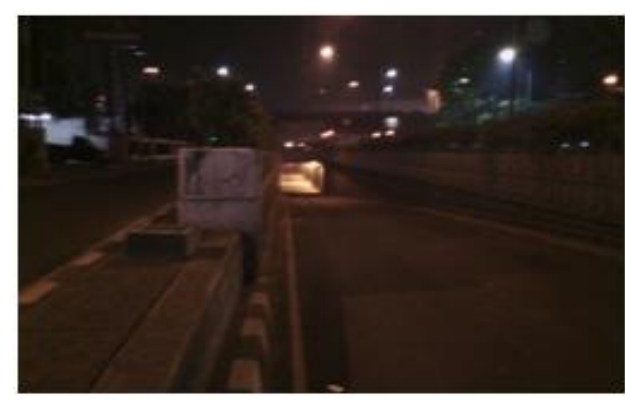

(c) Suasana menuju terowongan

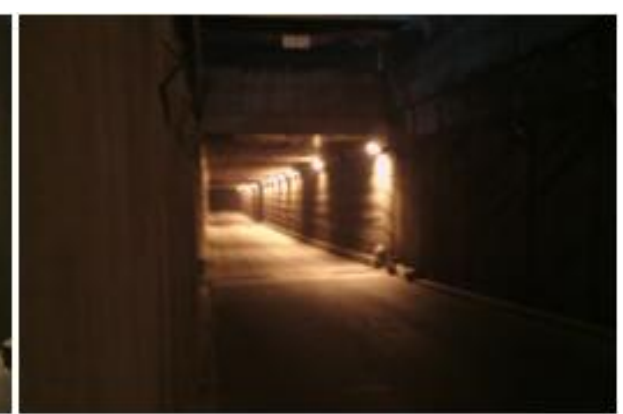

(b) Zona akses menuju terowongan

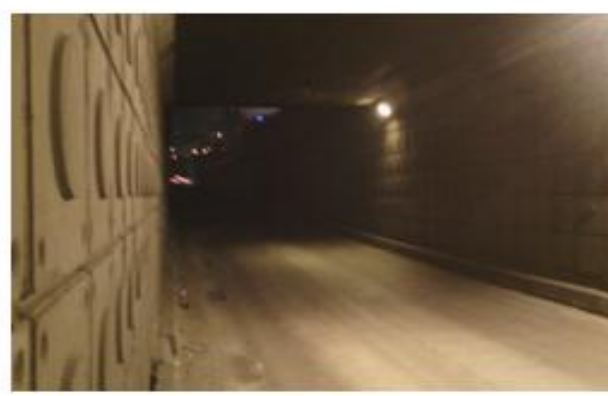

(d) Dari zona exit ke luar terowongan

Gambar 1. Pencahayaan terowongan Tomang pada malam hari. (Setyaningsih, 2014)
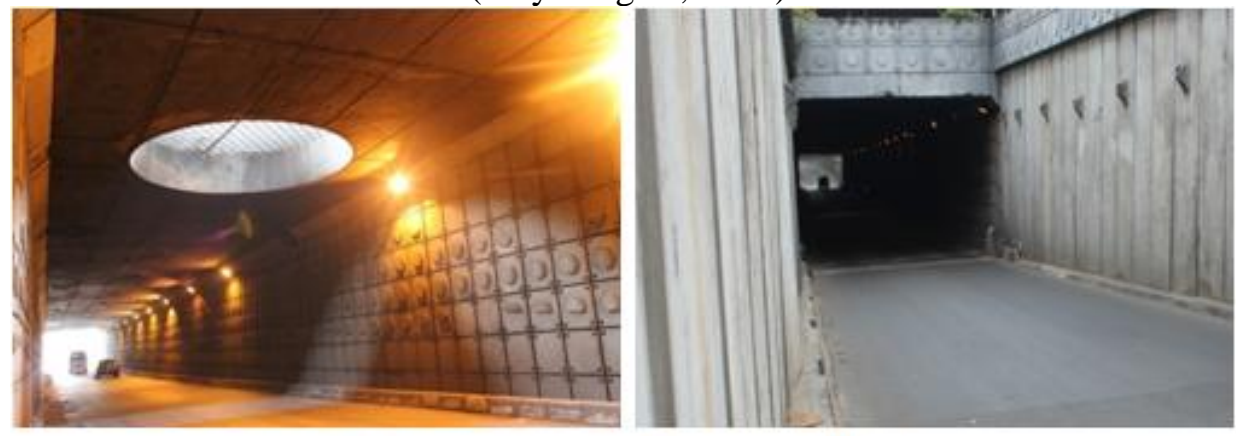

(a) Semua zona terowongan

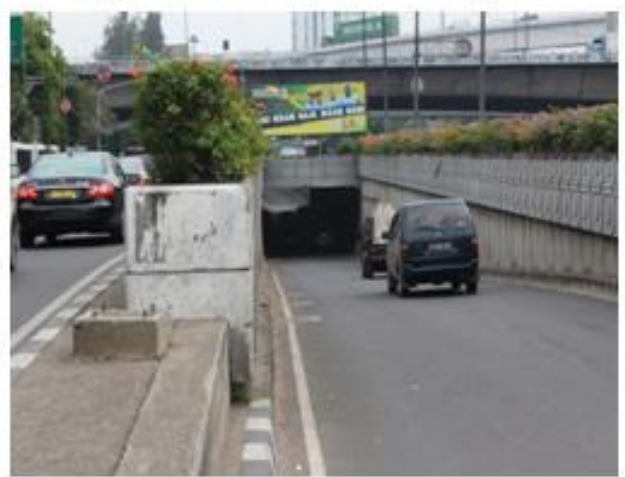

(b) Zona akses menuju terowongan

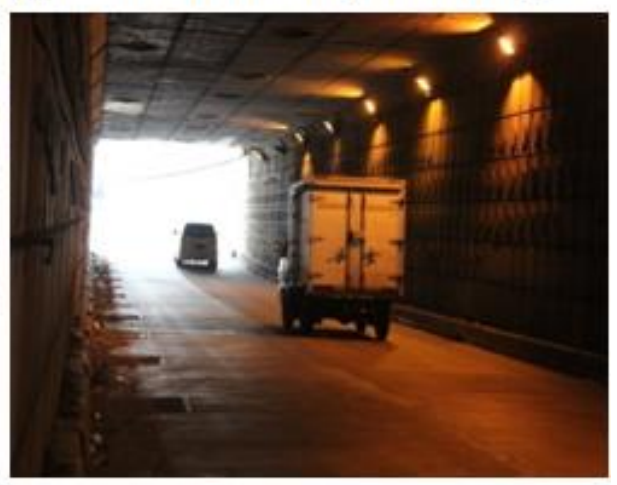

(c) Suasana menuju terowongan

(d) Dari zona exit ke luar terowongan

Gambar 2. Pencahayaan terowongan Tomang pada siang hari (Setyaningsih, 2014)

Gambar 1 menunjukkan pencahayaan terowongan Tomang pada malam hari. Gambar 1a pencahayaan pada semua zona, yang lebih tinggi iluminansi dan luminansinya dari pada cahaya sebelum dan sesudah 
terowongan seperti terlihat pada Gambar 1b, 1c dan 1d. Gambar 2 adalah pencahayaan tomang siang hari, yang menunjukkan hal yang berlawanan dari pada siang hari, yaitu pencahayaan di zona akses jauh lebih besar dari pada di zona threshold. Kondisi pencahayaan seperti ini kurang baik untuk penglihatan

pengguna kendaraan yang akan melewati/masuk terowongan, yaitu pengendara akan mengalami kehilangan orientasi sesaat karena mata akan mengalami perubahan cahaya

yang mendadak dari gelap ke terang dan sebaliknya pada saat keluar terowongan. Pengambilan gambar/foto di atas dilakukan dari arah Jakarta menuju arah Tangerang, terlihat bahwa deretan lampu dipasang pada salah satu dinding bagian kanan terowongan dengan sistem pemasangan wall mounting asymmetrical lighting (Torn, 2004). Terowongan Tomang termasuk dalam tipe devided tunnel yaitu satu arah lalu lintas. Luminansi malam hari pada terowongan tipe devided tunnel adalah $2,5 \mathrm{~cd} / \mathrm{m}^{2}$, nilai Luminansi ini dapat dikonversi ke nilai iluminansi dengan dibagi dengan angka 0,095 .

Angka ini diperoleh dari tabel 8 pedoman pencahayaan untuk terowongan ANSI/IES Rp-22-11, dengan faktor refleksi dinding 30\%, karena dinding terowongan tomang terbuat dari semen (Portland Cement Concrete/PCC dengan faktor refleksi antara $20 \%$ sd $40 \%$ (Torn, 2004), maka besarnya iluminansi adalah 26,32 lux (sedangkan rata-rata iluminansi pada terowongan Tomang adalah 104 lux). Jadi iluminansi pada terowongan tomang 4 kali lebih besar dari standar ANSI/IES Rp-22-11dan 5 kali lebih besar daripada standar SNI.

\section{KAJIAN PUSTAKA}

Terowongan adalah jalan yang sekelilingnya tertutup oleh struktur, umumnya elevasi jalan tersebut di bawah permukaan tanah [Departemen PU, 2009]. Kata terowongan dalam bahasa Indonesia mempunyai 2 padanan kata dalam bahasa Inggris yaitu underpass dan tunnel. Terowongan dapat dibagi menjadi "terowongan panjang" dan "terowongan pendek" berdasarkan kejelasan pandangnya. Terowongan pendek adalah terowongan yang jalan keluarnya terlihat jelas dari suatu titik tepat di muka jalan masuk terowongan, saat tidak ada kendaraan yang melintas. Biasanya panjang terowongan pendek dibatasi sampai 75 meter [CIE, 2004]. Pada siang hari terowongan pendek umumnya tidak membutuhkan sistem pencahayaan karena masuknya cahaya matahari di siang hari dari kedua sisi terowongan pendek, ditambah efek siluet dari terang cahaya ujung terowongan yang lain, secara umum menjamin jarak pandang yang memuaskan. Sebaliknya pada terowongan panjang, pengemudi tidak dapat melihat ujung keluar dari terowongan. Terowongan yang panjangnya kurang dari $75 \mathrm{~m}$ tetapi jalurnya tidak lurus sehingga pengemudi tidak dapat melihat ujung keluar terowongan, didefinisikan sebagai terowongan panjang. Terowongan panjang secara optikal: terowongan yang panjangnya kurang dari $75 \mathrm{~m}$ tetapi pengemudi tidak dapat melihat ujung keluar dari terowongan sehingga memerlukan pencahayaan buatan.

Tujuan dasar pencahayaan terowongan adalah untuk memberikan jarak pandang yang cukup dan nyaman bagi pengguna terowongan sehingga pengguna terowongan dapat melalui terowongan dengan aman, baik di siang hari maupun di malam hari [CIE, 2004]. Untuk mencapai tujuan tersebut, ada beberapa hal yang harus dipertimbangkan [Nordick Vejteknisk Forbund, 1995 dan ANSI/IES RP-22-11, 2011]: pencahayaan harus memberikan tingkat iluminansi yang cukup dan merata pada pengemudi di sepanjang terowongan baik pada kondisi kering maupun basah, sudut datangnya cahaya lampu relative terhadap penglihatan pengemudi, harus memberikan tingkat penglihatan yang tinggi terhadap marka jalan dalam semua kondisi cuaca, pencahayaan tidak boleh menimbulkan silau (silau), dan pencahayaan tidak boleh berkedip-kedip (flicker)

Kemampuan mata manusia dalam mengadaptasi perubahan tingkat pencahayaan dari terang ke gelap tidak secepat mengadaptasi perubahan tingkat pencahayaan dari gelap ke terang. Hal ini yang disebut sebagai kondisi black out. Untuk itu tingkat pencahayaan pada terowongan panjang dibagi menjadi 5 zona yang berbeda, seperti ditunjukkan pada Gambar 3. 


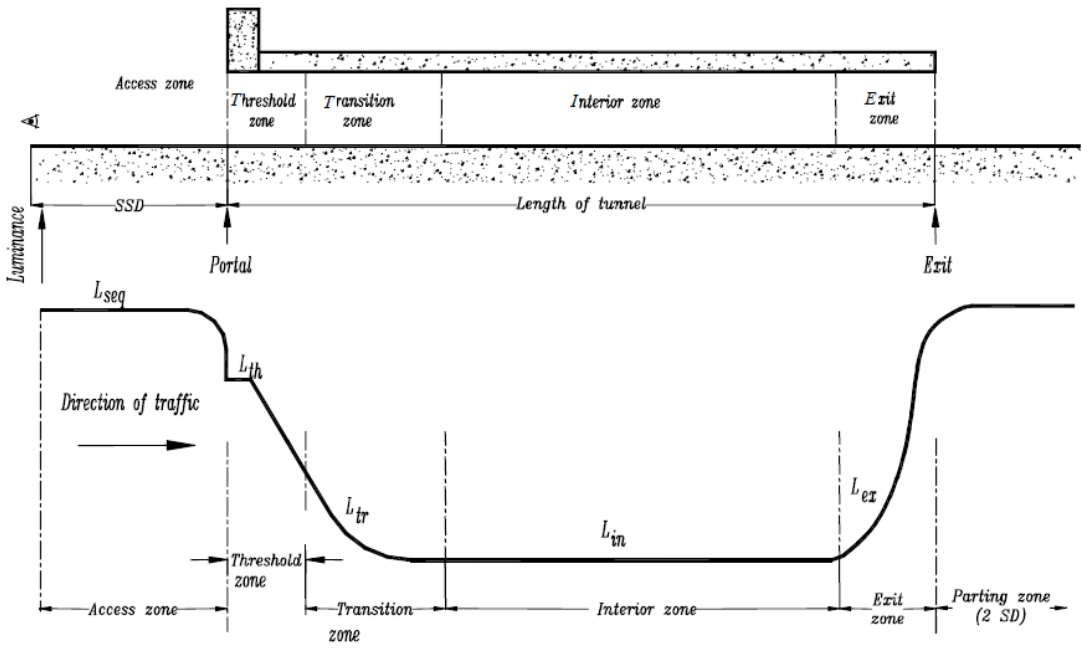

Gambar 3. Pembagian Zona Terowongan [CIE, 2004]

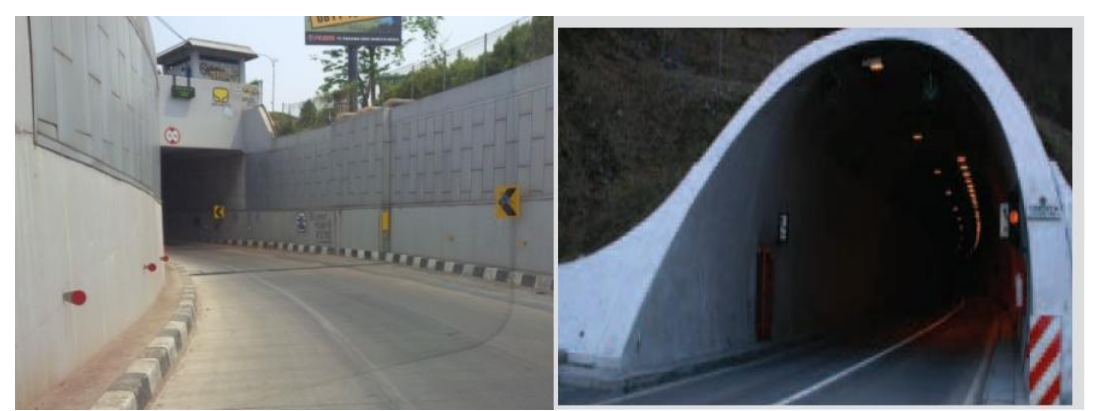

Gambar 4 (a) Zona Akses Terowongan Cibubur (Setyaningsih, 2015)

(b) Zona ambang terowongan [Thorn, 2004]

Zona akses adalah bagian dari jalan yang menuju mulut terowongan. Pada zona inilah pengemudi dapat melihat adanya terowongan. Tingkat pencahayaannya sama dengan tingkat pencahayaan lingkungan di luar terowongan. Gambar 4a. merupakan contoh zona akses dari terowongan Cibubur.

1. Zona ambang/threshold adalah bagian dari jalan tempat pengemudi dapat melihat ke dalam terowongan. Panjang zona ambang sama dengan panjangnya jarak henti kendaraan (stopping distance), sehingga tergantung dari kecepatan kendaraan maksimum yang diijinkan di dalam terowongan. Semakin tinggi kecepatan kendaraan yang melintas, maka zona inipun semakin panjang. Pengemudi yang berada di zona akses harus dapat mendeteksi rintangan-rintangan di zona ambang sebelum pengemudi memasuki terowongan. Gambar 4b. menunjukkan zona ambang terowongan dan Gambar 3 juga menunjukkan tingkat pencahayaan pada zona ambang secara gradual akan berkurang.

2. Zona Transisi adalah zona tempat terjadinya transisi tingkat pencahayaan, yang semula relatif tinggi di zona ambang kemudian menjadi jauh lebih rendah di zona interior. Transisi tingkat kuat pencahayaan ini terjadi secara bertahap. Panjang zona ini adalah fungsi dari kecepatan lalu-lintas maksimum yang telah ditentukan dan perbedaan tingkat pencahayaan antara akhir zona ambang dan awal zona interior.

3. Zona interior adalah bagian terowongan yang terletak di bagian dalam terowongan sehingga tidak mendapat pengaruh cahaya matahari yang signifikan. Penglihatan pengemudi, pada zona ini, hanya diberikan oleh pencahayaan buatan. Zona interior memiliki satu sifat khusus yaitu tingkat pencahayaan yang konstan di seluruh zona. Tingkat pencahayaan di zona interior dapat dilihat pada Tabel 1, yaitu untuk terowongan panjang (CIE, 2004). Bila menggunakan Standar ANSI/IESNA RP-22-11, dapat dilihat pada Tabel 2.

4. Zona keluar (exit) adalah zona paling akhir tempat pengemudi keluar dari terowongan, tingkat pencahayaan pada zona ini secara linier meningkat sehingga mencapai tingkat cahaya alami di luar terowongan. 
Tabel 1. Luminansi $\left(\mathrm{cd} / \mathrm{m}^{2}\right)$ untuk zona interior pada terowongan panjang [CIE, 2004]

\begin{tabular}{|c|c|c|}
\hline \multirow{2}{*}{$\begin{array}{c}\text { Jarak henti } \\
{[\mathrm{m}]}\end{array}$} & \multicolumn{2}{|c|}{$\begin{array}{c}\text { Terowongan panjang } \\
\text { Laju kendaraan [kendaraan/jam/lajur] }\end{array}$} \\
\cline { 2 - 3 } & Rendah & Tinggi \\
\hline $160 \mathrm{~m}$ & 6 & 6 \\
\hline $60 \mathrm{~m}$ & 3 & 10 \\
\hline
\end{tabular}

Tabel 2. Recommended Daytime Interior Zone Average Pavement Luminance dalam $\mathrm{cd} / \mathrm{m}^{2}$ (Standar ANSI/IESNA RP-22-11).

\begin{tabular}{|c|c|c|c|}
\hline \multirow{2}{*}{ Traffic Speed } & \multicolumn{3}{|c|}{ Traffic Flow } \\
\cline { 2 - 4 } & $<2,400$ AADT & $\begin{array}{r}>2,400 \text { AADT } \\
<24,000 \text { AADT }\end{array}$ & $>24,000$ AADT \\
\hline $100 \mathrm{~km} / \mathrm{h}(60 \mathrm{mph})$ & 6 & 8 & 10 \\
\hline $80 \mathrm{~km} / \mathrm{h}(50 \mathrm{mph})$ & 4 & 6 & 8 \\
\hline $60 \mathrm{~km} / \mathrm{h}(40 \mathrm{mph})$ & 3 & 4 & 6 \\
\hline
\end{tabular}

Catatan: ADDT = Annual Average Daily Traffic (Lalu Lintas Harian Rata-Rata Tahunan)

Pencahayaan terowongan di siang hari berbeda dari pencahayaan terowongan di malam hari. Faktor-faktor yang mempengaruhi pencahayaan terowongan adalah: [IESNA, 2010]: Kendali pencahayaan, silau, kemerataan, dan kedip (flicker). Untuk pencahayaan terowongan pada malam hari, pemecahan masalahnya lebih sederhana karena berasal dari pencahayaan buatan seluruhnya. Ada dua hal yang perlu dipertimbangkan [CIE, 2004]:

1. Jika terowongan adalah bagian dari jalan raya yang diberi penerangan maka kualitas cahaya di dalam terowongan sedikitnya harus sama dengan kualitas cahaya di luar terowongan, sehingga membentuk tingkat pencahayaan yang merata.

2. Jika terowongan bukan merupakan bagian dari jalan raya yang diterangi, maka luminansi di permukaan jalan raya minimal sebesar $1 \mathrm{~cd} / \mathrm{m}^{2}$.

Tabel 3. Kuat/Tingkat Pencahayaan dan Luminansi Penerangan Jalan Umum (SNI 7391:2008, BSN)

\begin{tabular}{|c|c|c|c|c|c|c|c|}
\hline \multirow{3}{*}{$\begin{array}{c}\text { Jenis/ } \\
\text { klasifikasi jalan }\end{array}$} & \multicolumn{2}{|c|}{$\begin{array}{c}\text { Kuat pencahayaan } \\
\text { (Iluminansi) }\end{array}$} & \multicolumn{3}{|c|}{ Luminansi } & \multicolumn{2}{|c|}{ Batasan silau } \\
\hline & \multirow{2}{*}{$\begin{array}{l}\mathrm{E} \\
\text { rata- } \\
\text { rata } \\
\text { (lux) }\end{array}$} & \multirow{2}{*}{$\begin{array}{c}\begin{array}{r}\text { Kemerataan } \\
\text { (Uniformity) }\end{array} \\
\mathrm{g} 1\end{array}$} & \multirow[t]{2}{*}{$\underset{\substack{\text { rata-rata } \\
(\mathrm{cd} / \mathrm{m} 2)}}{\mathrm{L}}$} & \multicolumn{2}{|c|}{$\begin{array}{l}\text { Kemerataan } \\
\text { (uniformity) }\end{array}$} & \multirow[t]{2}{*}{$\mathbf{G}$} & \multirow[t]{2}{*}{$\begin{array}{l}\text { TJ } \\
\text { (\%) }\end{array}$} \\
\hline & & & & VD & VI & & \\
\hline Trotoar & $1-4$ & 0,10 & 0,10 & 0,40 & 0,50 & 4 & 20 \\
\hline $\begin{array}{l}\text { Jalan lokal : } \\
\text { - Primer } \\
\text { - Sekunder }\end{array}$ & $\begin{array}{l}2-5 \\
2-5\end{array}$ & $\begin{array}{l}0,10 \\
0,10\end{array}$ & $\begin{array}{l}0,50 \\
0,50\end{array}$ & $\begin{array}{l}0,40 \\
0,40\end{array}$ & $\begin{array}{l}0,50 \\
0,50\end{array}$ & $\begin{array}{l}4 \\
4\end{array}$ & $\begin{array}{l}20 \\
20\end{array}$ \\
\hline $\begin{array}{l}\text { Jalan kolektor : } \\
\text { - Primer } \\
\text { - Sekunder }\end{array}$ & $\begin{array}{l}3-7 \\
3-7\end{array}$ & $\begin{array}{l}0,14 \\
0,14\end{array}$ & $\begin{array}{l}1,00 \\
1,00\end{array}$ & $\begin{array}{l}0,40 \\
0,40\end{array}$ & $\begin{array}{l}0,50 \\
0,50\end{array}$ & $\begin{array}{l}4-5 \\
4-5\end{array}$ & $\begin{array}{l}20 \\
20\end{array}$ \\
\hline $\begin{array}{l}\text { Jalan arteri : } \\
\text { - Primer } \\
\text { - Sekunder }\end{array}$ & $\begin{array}{l}11-20 \\
11-20\end{array}$ & $\begin{array}{l}0,14-0,20 \\
0,14-0,20\end{array}$ & $\begin{array}{l}1,50 \\
1,50\end{array}$ & $\begin{array}{l}0,40 \\
0,40\end{array}$ & $\begin{array}{l}0,50-0,70 \\
0,50-0,70\end{array}$ & $\begin{array}{l}5-6 \\
5-6\end{array}$ & $\begin{array}{l}10-20 \\
10-20\end{array}$ \\
\hline $\begin{array}{l}\text { Jalan arteri dengan } \\
\text { akses kontrol, jalan } \\
\text { bebas hambatan }\end{array}$ & $15-20$ & $0,14-0,20$ & 1,50 & 0,40 & $0,50-0,70$ & $5-6$ & $10-20$ \\
\hline $\begin{array}{l}\text { Jalan layang, } \\
\text { simpang susun, } \\
\text { terowongan }\end{array}$ & $20-25$ & 0,20 & 2,00 & 0,40 & 0,70 & 6 & 10 \\
\hline
\end{tabular}

Keterangan g1 : E min/E maks ; VD : L min /L maks

$\mathrm{VI}: \mathrm{L} \mathrm{min} / \mathrm{L}$ rata-rata $; \mathrm{G}:$ Silau (glare)

TJ : Batas ambang kesilauan

Terdapat beberapa pengaturan susunan lampu dalam terowongan untuk mencapai tingkat pencahayaan yang sesuai 
yaitu [Thorn, 2004]: Ceiling mounting, yaitu pemasangan luminer di sepanjang atap/ceiling terowongan, bisa dipasang pada 1 line maupun 2 line dan wall mounting, yaitu pemasangan luminer di sepanjang dinding terowongan, biasanya dipasang dalam 2 line dikiri dan kanan terowongan. Teknik aplikasi cahaya lampu dipengaruhi oleh luminer, yang akan menentukan distribusi pencahayaan di terowongan. Terdapat 3 (tiga) teknik aplikasi cahaya, seperti pada Gambar 5 [ANSI/IES Rp-22-11, 2011] yaitu:

- Symmetrical Light Distribution distribusi cahaya simetri.

- Asymmetrical Light Distribution-Negative Contract (ALD-NC) dikenal juga sebagai Counterbeam Lighting (CBL), distribusi cahaya dominan menuju ke pengendara kendaraan, luminansi dipermukaaan jalan tinggi, arah cahaya searah kendaraan diminimalkan dan meningkatkan kontras negatif.

- Asymmetrical Light Distribution-Positive Contrast (ALD-PC) dikenal juga sebagai Pro-beam Lighting (PBL), arah cahaya dominan searah dengan lalu lintas, luminansi kea rah obyek tinggi dan luminansi di permukaan jalan mempunyai kontras yang positf.

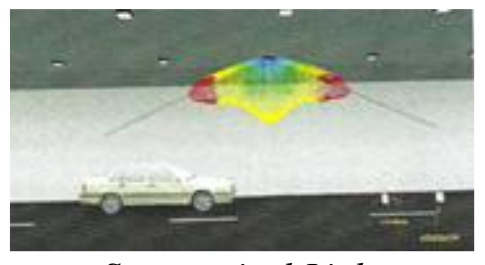

Symmetrical Light

Distribution

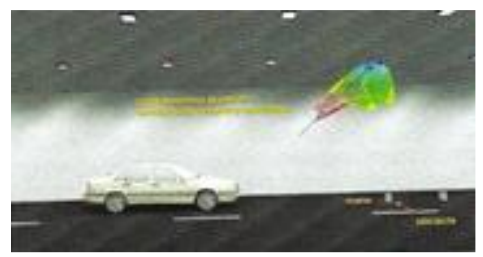

Asymmetrical Light

Distribution - Negative Contract

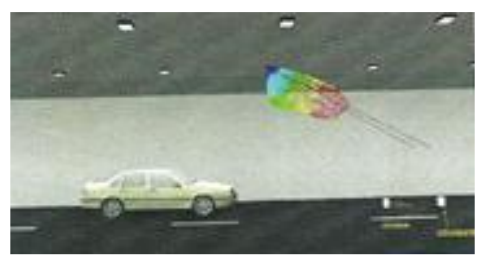

Asymmetrical Light

Distribution - Positive

Contrast

Gambar 5. Teknik Aplikasi cahaya lampu Terowongan

Karakteristik udara dalam terowongan berbeda dengan karakteristik udara di jalan raya biasa. Di dalam terowongan, konsentrasi gas buang kendaraan akan lebih tinggi dari jalan raya biasa karena pertukaran udara lebih lamban dibanding dengan jalan raya biasa. Dengan demikian lampu penerangan yang digunakan juga harus lebih tahan terhadap zat-zat berbahaya yang dikandung dalam gas buang kendaraan seperti asam sulfat, asam nitrat, karbon mono oksida dan sejenisnya. Beberapa jenis lampu yang direkomendasikan untuk digunakan sebagai lampu penerangan dalam terowongan adalah [Liu, 2005, Phadnis, 2012, SNI, 2008]: lampu fluorescent, lampu sodium tekanan rendah, lampu sodium tekanan tinggi, lampu merkuri tegangan tinggi, lampu LED (Light Emitting Diode), lampu induksi (Electrodeless lamps) [Buraczynski et al., 2010]

Lampu LED kurang disarankan untuk pencahayaan terowongan, karena pemasangannya yang kompleks, dan belum konsisten pada warna cahaya, umur lampu dan efikasinya. [Buraczynski et al., 2010], akan tetapi untuk saat ini sudah ada lampu LED yang digunakan sebagai PJU dengan kinerja yang baik [Fat, 2013]. Namun lampu LED tidak akan memberikan kinerja yang baik, bila dalam perencanaan, perancangan dan pemasangannya tidak optimal. Hal ini bisa dijumpai pada PJU di Jl. Antasari DKI Jakarta, yaitu penggunaan lampu LED yang berlebihan sehingga tingkat pencahayaan jauh melebihi standar Standar Nasional Indonesia (seperti pada Tabel 2.4) dan menimbulkan silau [Setyaningsih, 2013]. Namun sesuai perkembangan teknologi lampu LED, saat ini lampu LED sudah banyak digunakan dalam penerangan jalan umum maupun terowongan dan diharapkan akan menjadi lampu masa depan yang menggantikan lampu dengan teknologi sebelumnya. Lampu LED mempunyai umur lampu yang sangat panjang (sekitar $50.000 \mathrm{jam}$ ) dan mempunyai efikasi minimal 100 lumen/watt (Bommel, 2015).

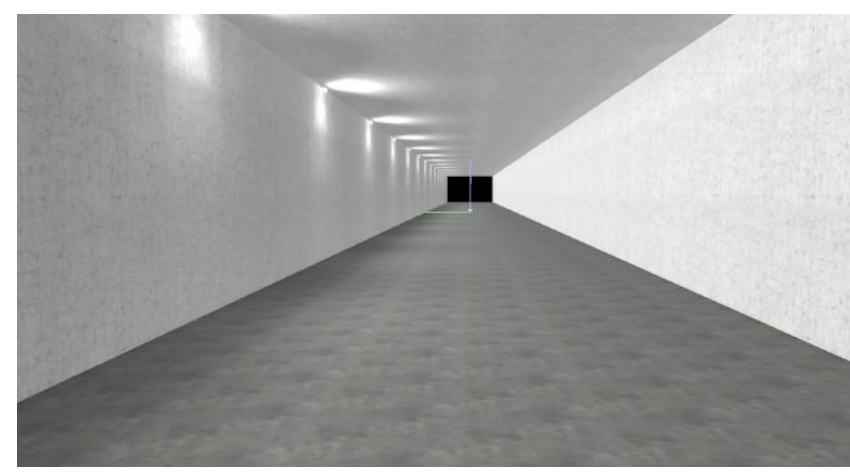

Gambar 6. Bentuk simulasi terowongan Tomang

HASIL SIMULASI DAN ANALISIS

Perancancangan berupa simulasi (dengan software Dialux) pada terowongan Tomang ini menggunakan tiga tipe lampu LED, yaitu BVP381 LED120CW SWB 100W, BVP381 LED120CW AMB 100W, dan BWP352 LED137NW 120W. BVP merupakan lampu sorot dengan Symetric Wide Beam (SWB) dan Asymatric Medium 
Beam (AMB) dan BWP merupakan lampu untuk terowongan, dengan pola distribusi yang lebih lebar, seperti juga yang digunakan untuk lampu jalan. Ketiga lampu ini menggunakan suatu merk tertentu ( $\mathrm{Ph})$, namun hanya sebatas untuk mendapatkan data (spesifikasi) dari lampu tersebut. Simulasi ini dilakukan untuk menganalisis pencahayaan terowongan Tomang yang saat ini menggunakan 15 buah lampu LED. Data ini diperoleh berdasarkan informasi sebagai berikut: "Diketahui bahwa sampai saat ini, telah dilakukan pemasangan 15 lampu LED dalam rangka menyambut Asian Games pada terowongan Tomang (Sumber: Kepala Suku Dinas Perindustrian dan Energi (PE) Jakarta Barat, Ery Ghazali, 4 Juli 2018, Poskota News)".

Gambar 6 adalah simulasi terowongan Tomang dan Gambar 7 adalah grafik luminansi terhadap jarak pada terowongan Tomang malam hari dan terlihat bahwa nilai luminansi rata-rata pada, yaitu $10 \mathrm{~cd} / \mathrm{m} 2$, lampu LED yang digunakan adalah tipe BWP352 LED137NW 120W. Untuk malam hari nilai ini jauh lebih besar daripada standar SNI yaitu $2 \mathrm{~cd} / \mathrm{m} 2$. Hal ini mengidikasikan bahwa terjadi pemborosan energi listrik, untuk itu perlu diturunkan intensita cahaya untuk malam hari, dengan menggunakan pengendali cahaya.

Selain itu tampak dari Gambar 7 bahwa terjadi pencahayaan yang kurang merata, yang berupa luminansi yang lebih tinggi pada area di bawah lampu dan luminansi yang menurun pada area diantara 2 lampu, sehingga luminansi di semua zona tampak seperti gelombang sinus. Untuk itu jumlah lampu dapat ditambah, namun fluks cahaya lampu (lumen) dapat diturunkan, sehingga jarak lampu dapat diperkecil.

Selanjutnya jika menggunakan jumlah lampu LED 15 buah yang terpasang saat ini, digunakan untuk simulasi pencahayaan siang hari dan masing-masing menggunakan tipe lampu LED yang berbeda, hasilnya seperti pada Gambar 8 sampai dengan Gambar 10. Gambar 11 merupakan perbandingan dari simulasi menggunakan 3 tipe lampu LED tersebut dan Tabel 3 menunjukkan rekapitulasi hasil simulasinya. Tampak bahwa luminansi di zona eksis yang tinggi, tidak diikuti oleh luminansi di zona ambang, sehingga luminansi tiba-tiba turun tajam ke luminansi zona interior, tanpa adanya pencahayaan di zona transisi. Pencahayaan terowongan seperti ini kurang memenuhi standar, karena akan menyebabkan pandangan visual pengendara mobil saat akan masuk ke terowongan mengalami perubahan cahaya yang sangat tajam antara zona akses diluar terowongan dengan luminansi yang tinggi dari cahaya matahari, ke luminansi yang rendah di zona ambang, dan tanpa adanya pencahayaan transisi ke zona interior. Demikian sebaliknya pada arah keluar terowongan,

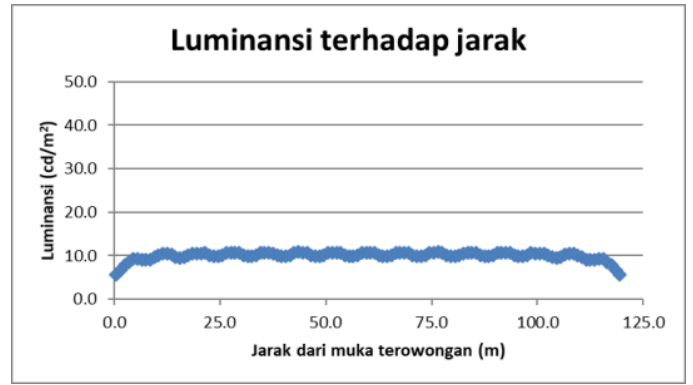

Gambar 7. Hasil simulasi luminansi terhadap jarak pada terowongan Tomang malam hari

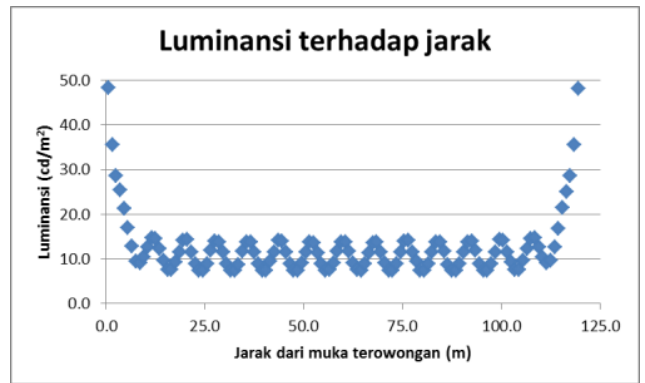

Gambar 8. Hasil simulasi pencahayaan terowongan Tomang siang hari menggunakan tipe lampu LED BVP381 SWR

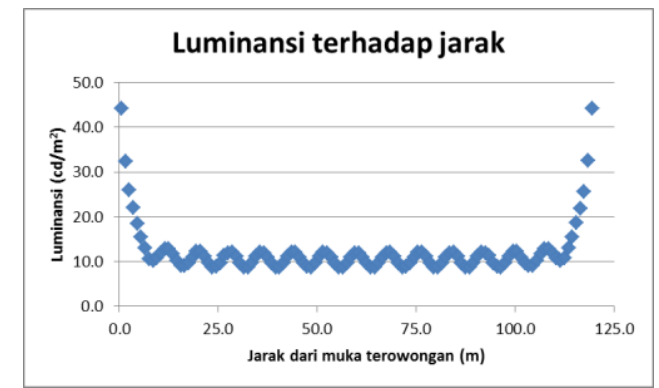

Gambar 9. Hasil simulasi pencahayaan terowongan Tomang siang hari menggunakan tipe lampu LED BVP381 AMB

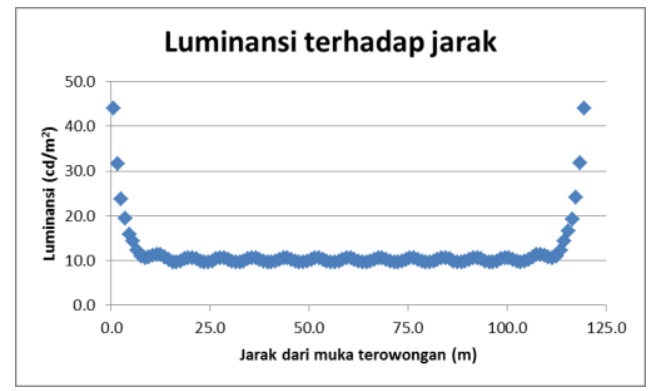

Gambar 10. Hasil simulasi pencahayaan terowongan Tomang siang hari menggunakan tipe lampu LED BWP352

pandangan visual pengendara mobil mendadak berubah ke pencahayaan dengan luminansi yang sangat tinggi di zona keluar. Pencahayaan siang hari ini juga tidak merata, yang terlihat dari perbedaan yang sangat tinggi antara luminansi terendah terhadap luminansi maksimal.

Berdasarkan hasil analisis di atas, maka pencahayaan terowongan Tomang pada siang hari perlu dilakukan perbaikan. Perbaikan terutama untuk pencahayaan di zona ambang dan zona transisi, sehingga pengendara mobil tidak mengalami kehilangan pandangan visual secara mendadak, yang diharapkan tidak terjadi 
black hole fenomenon. Gambar 12 adalah hasil perbaikan simulasi pencahayaan terowongan Tomang siang hari menggunakan lampu LED tipe BWP352 dan Tabel 4 adalah hasil rekapitulasinya. Terlihat bahwa pada zona ambang (threshold zone), nilai luminansinya adalah $31,11 \mathrm{~cd} / \mathrm{m} 2$ untuk jarak 0 sampai dengan $20 \mathrm{~m}$ dari muka terowongan, dan jumlah lampu yang dibutuhkan adalah 4 buah dengan daya 240 watt. Luminansi zona transisi $20,76 \mathrm{~cd} / \mathrm{m} 2$, untuk jarak $21 \mathrm{~m}$ sampai dengan $40 \mathrm{~m}$, dengan jumlah lampu yang dibutuhkan adalah 4 buah dengan daya 150 watt. Zona interior yaitu pada jarak $41 \mathrm{~m}$ sampai dengan $120 \mathrm{~m}$ (batas akhir terowongan) membutuhkan 10 buah lampu LED dengan daya 100 watt, dan diperoleh luminansi sebesar 9,06 cd/m2. Nilai luminansi ini lebih besar daripada standar internasional [ANSI/IES Rp-22-11, 2011], yaitu $6 \mathrm{~cd} / \mathrm{m}^{2}$, untuk kecepatan kendaraan 80 km/jam dan Lalu Lintas Harian Rata-Rata Tahunan (AADT) > 2,400 AADT< 24,000 AADT (lihat Tabel 2).

Pencahayaan untuk seluruh panjang terowongan membutuhkan 18 buah lampu dengan daya dan luminansi yang berbeda tiap zona, total daya adalah 2560 watt. Pemasangan lampu saat ini hanya ada satu deret yang diletakkan di sudut antara dinding dan langit-langit terowongan, dengan luminer dipasang secara menempel (ceiling mounted). Perbaikan simulasi ini masih perlu dilakukan lagi, sehingga besarnya luminansi di zona interior bisa mencapai $6 \mathrm{~cd} / \mathrm{m}^{2}$ sesuai standar [ANSI/IES Rp-22-11, 2011]. Selain itu luminer bisa diletakan dalam dua deret, yaitu di bagian sudut kanan dan kiri atau dua deret di langit-langit. Diharapkan pemasangan ini menghasilkan pemerataan pencahayaan di permukaan jalan pada terowongan.

Analisis pencahayaan terowongan siang hari ini, tidak menggunakan standar SNI 7391:2008 (lihat Tabel 3), karena nilai luminansi dalam SNI tidak disebutkan untuk siang atau malam hari. Namun dengan nilai luminansi sebesar $2 \mathrm{~cd} / \mathrm{m}^{2}$ dapat diasumsikan nilai luminansi tersebut lebih tepatnya untuk pencahayaan terowongan malam hari. Untuk itu perlu menjadi pertimbangan bahwa standar SNI ini untuk segera direvisi. Mengingat seperti yang disebutkan di atas, juga SNI ini dikeluarkan oleh Badan Standardisasi Nasional (BSN) tahun 2008. Pada tahun tersebut lampu LED belum digunakan dalam pencahayaan terowongan. Biasanya untuk pencahayaan terowongan saat itu menggunakan lampu High Pressure Sodium/HPS (Setyaningsih, 2014) dengan kesan warna kekuningan atau lampu jenis metal halide dengan kesan warna putih.

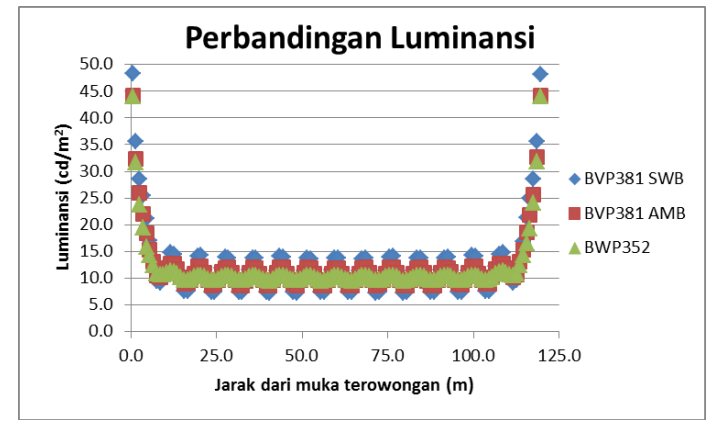

Gambar 11. Simulasi Perbandingan

Luminansi terhadap jarak terowongan Tomang siang hari menggunakan 3 tipe lampu LED.

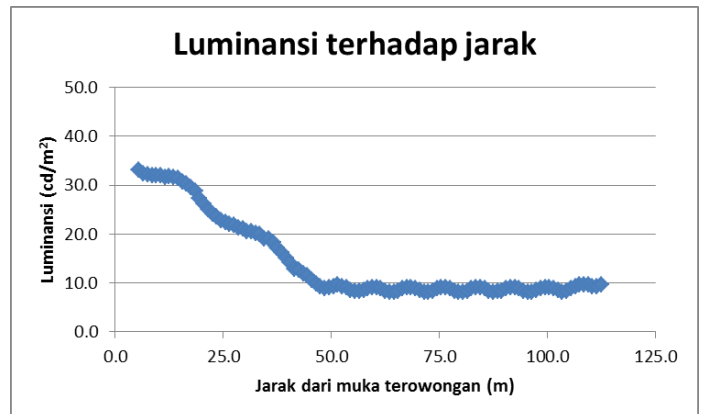

Gambar 12. Hasil perbaikan simulasi pencahayaan terowongan Tomang siang hari menggunakan lampu LED tipe BWP352

Tabel 4. Rekapitulasi hasil perbaikan simulasi pencahayaan terowongan Tomang siang hari dengan lampu LED tipe BWP352

\begin{tabular}{cc}
\hline Terowongan & Tomang \\
\hline Luminer (tipe lampu LED) & $4 \times$ BWP352 240W \\
& $4 x$ BWP352 150W \\
& $10 x$ BWP352 100W \\
\hline Total Daya & 2560 Watt \\
\hline Luminansi rata-rata zona: & \\
$\bullet \quad$ Threshold (0-20 meter) & $31.11 \mathrm{~cd} / \mathrm{m}^{2}$ \\
$\bullet \quad$ Transisi (21-40 meter) & $20.76 \mathrm{~cd} / \mathrm{m}^{2}$ \\
$\bullet \quad$ Interior (41-120 meter) & $9.06 \mathrm{~cd} / \mathrm{m}^{2}$ \\
\hline
\end{tabular}

\section{KESIMPULAN DAN SARAN}

Pemasangan lampu LED terowongan Tomang saat ini kurang tepat untuk pencahayaan siang hari, karena lampu diletakkan dengan jarak yang sama di tiap-tiap zona terowongan dan dengan fluks cahaya (satuan lumen)/daya yang sama. Jika untuk malam hari peletakkan lampu saat ini sudah sesuai, namun iluminansi dan luminansinya jauh lebih besar dari SNI yaitu 104 lux dan luminansinya $9,96 \mathrm{~cd} / \mathrm{m} 2$ sedangkan SNI sebesar 25 lux dan $2 \mathrm{~cd} / \mathrm{m}^{2}$. 
Hal ini mengidikasikan bahwa terjadi pemborosan energi listrik, untuk itu perlu diturunkan intensitas cahaya untuk malam hari, dengan menggunakan pengendali cahaya, atau penurunan fluks cahaya.

Pemasangan lampu LED pada zona ambang terowongan Tomang saat ini kurang dapat memenuhi luminansi cahaya matahari. Akibatnya pada siang hari zona ambang akan terasa gelap. Perbaikan perancangan melalui simulasi dihasilkan luminansi di zona ambang pada jarak 0-20 meter, adalah $31.11 \mathrm{~cd} / \mathrm{m}^{2}$.

Perancangan selanjutnya dapat mempertimbangkan pemasangan luminer dua deret, pada sudut-sudut antara dinding dan langit-langit terowongan atau dua deret di langit-langit, untuk memperoleh pencahayaan di permukaan jalan di terowongan yang lebih merata.

\section{DAFTAR PUSTAKA}

[1] Buraczynski, John J.; Li, Thomas K.; Kwong, Chris; and Lutkevich, Paul J., 2010. "Tunnel Lighting Systems" 4th International Symposium on Tunnel Safety and Security. Frankfurt Germany.

[2] Commision International de L'Ecclairage, 2004. "CIE Technical Report: Guide for Lighting Road Tunnels and Underpasses CIE 88-2004" 2nd Edition. Vienna: CIE Central Bureau.

[3] Departemen Pekerjaan Umum, Geometri Jalan Bebas Hambatan untuk Jalan Tol: Standar

[4] Kontstruksi dan Bangunan, Jakarta: Departemen Pekerjaan Umum, 2009, No. 007/BM, halaman 7.

[5] Fat, Joni; Setyaningsih, Endah; Zureidar, Ida; Wardhani, Lydwina., "Kinerja Lampu LED Terpasang untuk Jalan Non Tol DKI Jakarta", 2013, Lembaga Penelitian dan Publikasi Ilmiah, Universitas Tarumanagara.

[6] Illuminating Engineering Society, 2010. "IES Lighting Handbook", 9th edition.

[7] Illuminating Engineering Society of North America, 2011. "ANSI/IESNA RP-22-11: American National Standard Practice for Tunnel Lighting". New York: IESNA.

[8] Liu, Huo-Yen, 2005. "Design Criteria for Tunnel Lighting", World 2005 Long Tunnel.

[9] Nordisk Vejteknisk Forbund, 1995. "Road Tunnel Lighting: Common Nordic guidelines". Copenhagen: NVF.

[10] Phadnis, Mohit, 2012. "Lighting Design Of An Urbanised Tunnel"

[11] Setyaningsih, Endah; Zureidar, Ida; Susatyo, Budi., 2013, "Evaluasi Tata Pencahayaan Kawasan Jalan Non Tol Pangeran Antasari", Dinas Perindustrian dan Energi, DKI Jakarta.

[12] Setyaningsih, Endah; Pragantha, Jeanny; Wardhani, Lydwina, 2014, "Tunnel Lighting For Vehicles In DKI Jakarta”, The 17th FSTPT International Symposium, Jember University, 22-24 August 2014.

[13] SNI No. 7391-2008, Penerangan Jalan Umum, Badan Standarisasi Nasional, 2008.

[14] Setyaningsih, Endah dan Pragantha, Jeanny, 2015, Visual Performance Of Tunnel Lighting Along The Jakarta Outer Ring Road, International Conference on Engineering of Tarumanagara (ICET 2015), Faculty of Engineering, Universitas Tarumanagara, Jakarta-Indonesia, Oktober, 22-23, 2015.

[15] Thorn, 2004. "Tunnel Lighting". Hertfordshire: Thorn Lighting Main Office.

\section{UCAPAN TERIMAKASIH, KEPADA:}

- Kemenristek Dikti, atas bantuan dana hibah guna pelaksanaan penelitian 2018

- DPPM Universitas Tarumanagara, atas bantuan dana pendampingan guna memperlancar kegiatan penelitian ini. 